\title{
IoT based Control and Management of Thermal Power Plants for Robust Operation
}

\author{
A.Harish, S.Ashwin and S.Arunsenthil
}

\begin{abstract}
In today's world, the requirement for power is increasing with waxing population. So, it is necessary to have the capability of producing uninterrupted power to all the consumers. Among the solutions available in today's global market, Inter-Networking is considered to be most effective in terms of cost and efficiency [1]. As we start looking into the epitome of automation it exists as one single structure which can be implemented for a limited number of tasks, in order to overcome such barrier, the concept of Internet of Things (IoT) is utilized. IoT gives a simple and optimum solution to complex system's complex challenges. Although there are several tiny units of automated processes, there is no proper centralized control unit which can act as a backbone to connect these individual automated units to reduce the complexity of the system [2]. Internet of Things (loT) is an extension of the current internet to provide communication, connection, and internetworking between various devices or physical objects. In this paper, a novel application of Internet of Things in the automation of thermal power plant through simulation using contemporary tools has been proposed.
\end{abstract}

Keywords-IoT, Thermal Power plants, Automation Control, Industry 4.0, Autonomic computing and communication

\section{Introduction}

The Internet of Things (IoT) is a complex adaptive system consisting of sensors, processors, and controllers connected to a mainframe network. The sensors embedded in the target objects are connected to this network are highly intelligent and more capable of interacting with humans. The Internet of things extends the cloud computing concept beyond the existing computing and communication boundaries to include every aspect of the system irrespective of its existence. Generally, thermal power plants are commissioned in an extensively vast area that is near to its source of fuel with multiple mechanical pieces of equipment in position.

Hence, the wired communication lines for developing the network of mechanical components for data assimilation becomes more hectic, thereby deploying IoT into such industrial environment brings down the communication constraints extensively. This acts as the cognitive network to fetch, analyze, decide and communicate the data among the network created. Through a combination of advanced data analytics, IoT connects the machines, computers, and people to enable intelligent industrial operations. Industrial automation is a domain in which Internet of things can bring with many benefits. The real-time data collected from a large number of these interconnected hardware units can be used for

Harish .A, S.Ashwin and S.Arunsenthil

Sri Venkateswara College of Engineering, Anna University India the operation and maintenance of the thermal plants [2]. However, building a smart power plant results in many challenges, including both general IoT challenge such as security, and industrial automation domain specific requirements such as reliability and availability that remain to be fulfilled in the new IoT context. The main objective of this paper is to deploy internet of things concept in the today's power generation sector, i.e. Thermal power plants. This paper discusses some scenarios such as transportation of coal from the coal yard to bunker, monitoring power consumption of electrostatic precipitators and the motoring actions of the drives.

\section{Related Work}

Automation process enhances the current methodology into an isolated process without or with less interruption of humans. This kind of activity has a major impact in the Industrial 4.0 revolution. A Steel industry has enabled its continuous steel casting system with IoT and have achieved much higher efficiency [1]. [2] presents the technical solutions and best-practice guidelines adopted in the Padova Smart City project, a proof of concept deployment of an IoT island in the city of Padova, Italy, performed in collaboration with the city municipality. This also clearly explains the flawless way of communication between the devices over large areas. A detailed survey on the working, implementation, advantages and disadvantages of IoT is depicted in [7]. [8] gives the complete view on secure communication for smart IoT Objects.

\section{Proposed Method using IoT}

\section{A. Transportation of coal from coal yard to bunkers}

This process involves the movement of coal from the offshore unloader to boilers. This involves a number of stages between it- from offshore unloader to open yard coal storage, then to primary mills and to bunkers through the conveyor and the secondary mills. Now, this whole process is automated using internet of things. Appropriate sensors are placed in the required fields say, temperature sensor - to find the internal temperature of coal bunds, laser level sensors are placed inside the bunkers - to find the level of the coal, and on belt gamma sensors are placed on the conveyor belts - to find the presence of coal in the conveyor belt. The operation of this is as follows: the level sensors placed in the secondary bunkers. If this reads a value less than threshold value i.e. half of the capacity of the bunker, then these sensors send an intimation signal to the conveyors to fill these bunkers. The conveyor 


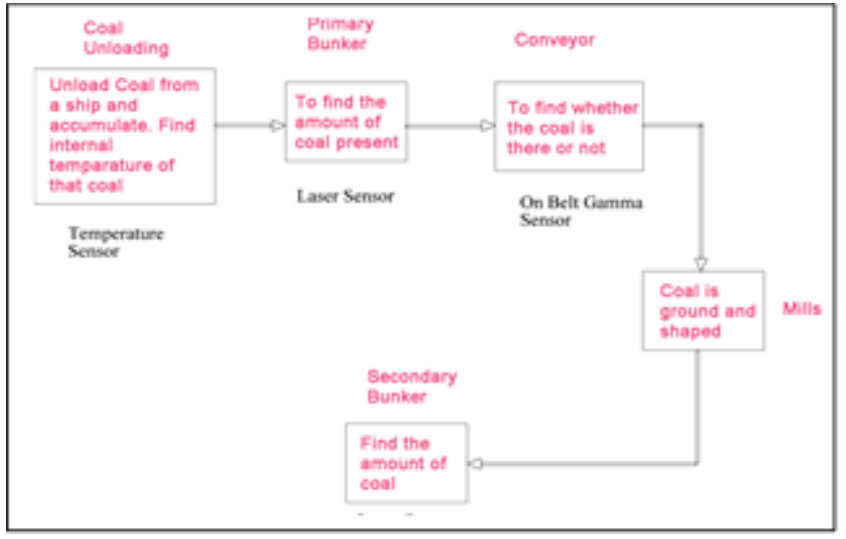

Figure 1. Block Diagram of Coal Transportation methodology

checks whether the conveyor is loaded with the coal using the on belt gamma sensors. If the conveyor is loaded and the bunker requests to fill, then the conveyor runs to fill this secondary bunker. The conveyor fills the secondary grinding mills which grind the coal and fills the secondary bunker with fine particles of coal. If the conveyor starts running the load in the belt reduces gradually, so the primary bunker starts to load the conveyor. The level sensors in the primary bunker pass a signal to the control room if the level of the primary bunker goes below a threshold value. The control room passes the information to the shore unloader to fill the primary bunker. Another scenario to be observed here is to maintain the internal temperature of the coal bunds in the open coal storage yard. In today's world, it is tough to address this scenario, and industries are using fire engines to control the fire upon an accident. But it can be easily solved using IoT technology, small temperature sensors can be placed the huge heap which transmits the temperature wirelessly to the nearby node. If the temperature exceeds the threshold values the sprinklers automatically sprinkles water to reduce its temperature. And the whole process from coal unloading to boiler is enhanced using WSN. Figure 1 illustrates the proposed idea.

Figure 2. Front Panel Diagram of Simulation Output

\section{B. Monitoring the Motoring action}

Thermal power plants have a number of electric drives for motoring action right from the importing of coal till ash handling. These devices are governed by the speed governors to have a control over these motors, which is also used to sense whether the motor is working. But in some remote areas such as zero meter slack conveyor (the ash collecting conveyors directly from the boiler) the huge ash blocks causes physical damage these external speed governor and intimate the control rooms as an emergency even during the normal function. To avoid this pathetic situation, it is proposed to embed an accelerometer in the rotor part of the motor drive which gives a three-coordinate graph during the rotation of the motor and shows nil if the motor is in OFF condition. This helps to avoid the emergency situation under normal operation condition. This is possible as Internet of Things can work using Wireless Sensor Nodes (WSN).

\section{Monitoring of Electrostatic precipitators}

The electrostatic precipitators are one of the most important arrangements in the thermal power plants to reduce the air pollution. The electrostatic precipitators (ESP) are the arrangement of long steel plates; it is supplied with high voltage. This repulses the ash particles and collects these in the separate containers without mixing with the air through the chimneys. The number of plates to be operated is directly proportional to the ash produced which is, in turn, proportional to the power production. Although this involves various parameters such as the calorific value of the coal, impurities present in coal, etc. But here it is neglected and assumed that power production is proportional to the ash produced. In this scenario internet of things is deployed to control the operation of a number of plates as per the requirement. A particle counter sensor is placed on the outlet of the chimney which is powered through the AC mains auxiliary supply. This sensor

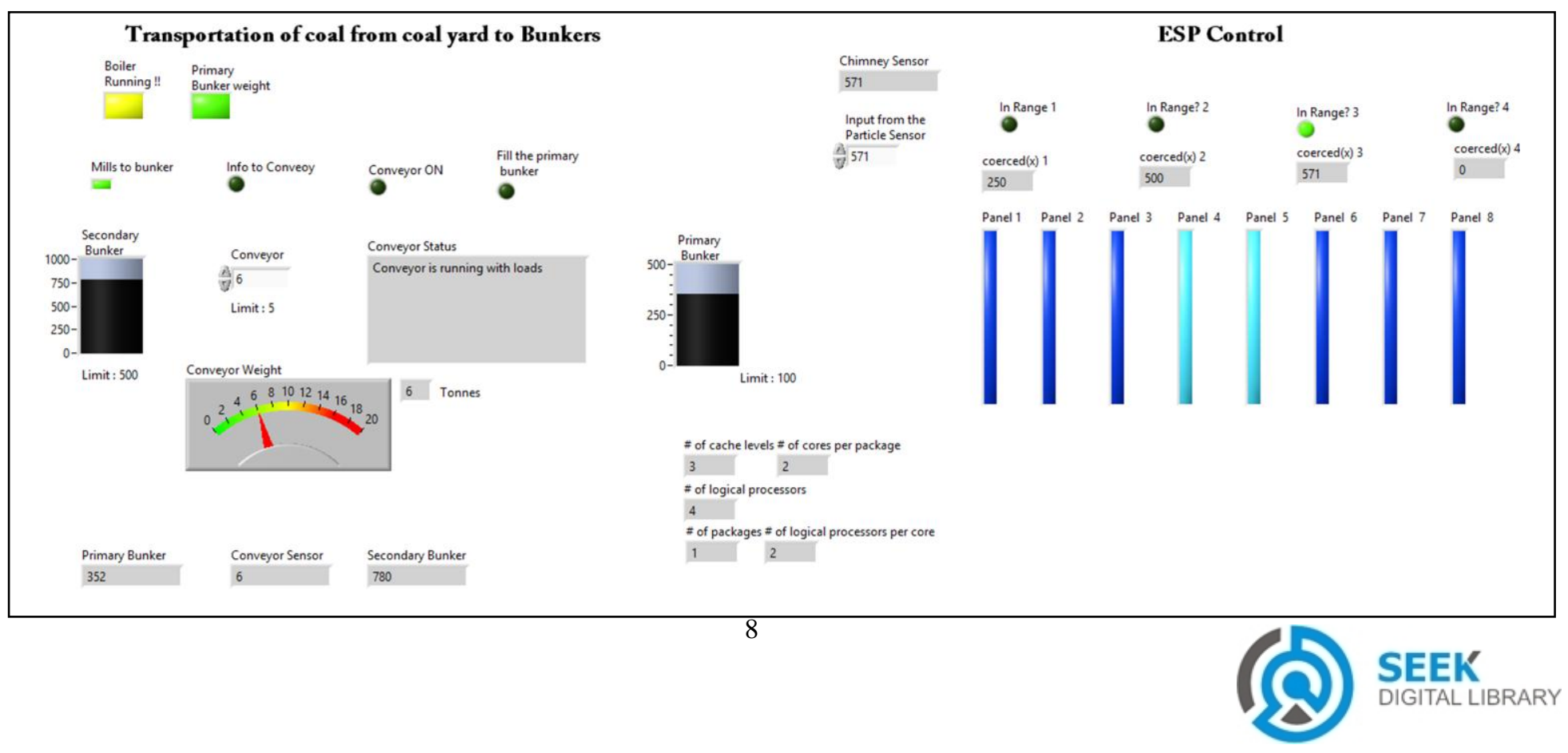


is directly connected to the ESP units wirelessly which inturn operates the ESP. Because of the unavailability of this technique now a huge amount of current is used as auxiliary consumption.

\section{Labview Simulation}

The ideas are also simulated in Laboratory Visual Instrument Engineering Workbench (LabVIEW). It is used for data acquisition, instrument control, and industrial automation For Simulation purposes, this paper uses the cloud monitoring technique accessible through the internet. Here a cloud platform - Ubidots has been used, which helps to send data, receive data and monitor the overall proposed system.

Figure 2 represents the front panel output diagram of the simulation and Figure 3 represents the back panel (Logic Diagram) of the simulation - LabVIEW.

\section{Iv. Architecture of the Communication System}

Since a Thermal Power plant spans several Square Kilometers the usual wireless technologies like Zigbee and Bluetooth -LE can't be used for communicating between various devices. Because of its short range communication and increased vulnerability of being hacked. Bluetooth connects to different devices i.e. even to employee mobile phones or some other nearby devices which would lead many misinterpretations.

\section{A. Various Wireless Standards for communication}

A new and upcoming standard of Wi-Fi called IEEE 802.11af fits the bill perfectly for this application. IEEE 802.11af, also referred to as White-Fi and Super Wi-Fi is a wireless computer networking standard in the 802.11 families, that allows wireless local area network (WLAN) operation in TV white space spectrum in the VHF and UHF bands between 54 and $790 \mathrm{MHz}$. Cognitive radio technology is used to transmit on unused portions of TV channel band allocations, with the standard taking measures to limit interference for primary users, such as analog TV, digital TV, and wireless microphones. Communication between IoT devices

\section{B. Description of IEEE 802.11 aft}

The physical (PHY) layer in 802.11af is based on the orthogonal frequency division multiplexing (OFDM) scheme specified in 802.11ac. The propagation path loss, as well as the attenuation by materials such as brick and concrete, is lower in the UHF and VHF bands than in the 2.4 and $5 \mathrm{GHz}$ bands, which increases the possible range compared to 802.11 $\mathrm{a} / \mathrm{b} / \mathrm{g} / \mathrm{n} / \mathrm{ac}$. The frequency channels are 6 to $8 \mathrm{MHz}$ wide, depending on the regulatory domain. Up to four channels may be bonded in either one or two contiguous blocks.

MIMO operation is possible with up to four streams used for either space-time block code (STBC) or multi-user (MUMIMO) operation. This wireless standard is geared towards

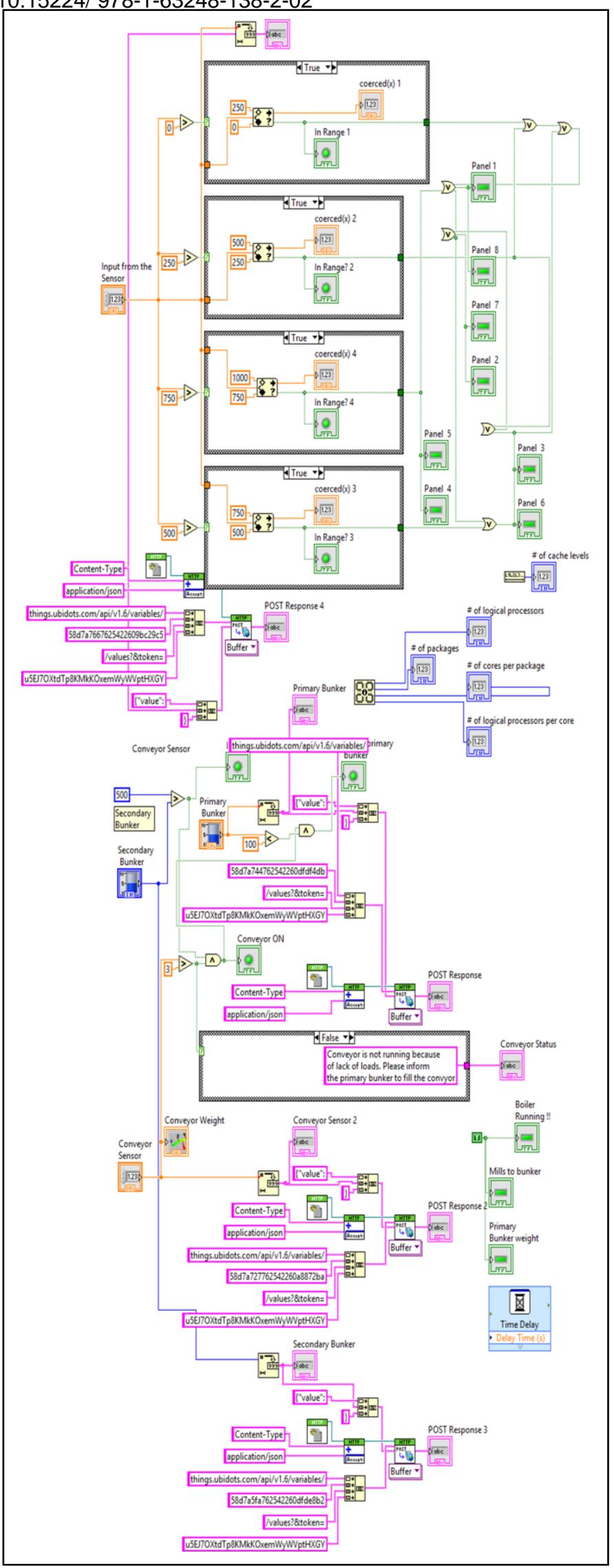

Figure 3. Back Panel Logic Diagram of Simulation 
the future IOT Devices which may be separated by a long distance.

Advantages: Because AF can use several unused TV channels at once, it can be utilized for very long range devices - potentially more than a Kilometer with high data rates. Because it isn't deployed in the mass market, interference and hackability are very low. Since many Thermal Power plants are pretty far from big cities, unused TV bands are available.

Other potential standards: In addition to 802.11 af, the IEEE has standardized another white space cognitive radio standard, 802.22. While 802.11af is a wireless LAN standard designed for ranges up to $1 \mathrm{~km}, 802.22$ is a wireless regional area network (WRAN) standard, for ranges up to $100 \mathrm{~km}$. This standard may be used in very large Thermal Power plants to serve as a reliable and secure channel for communication between various devices.

Communication Protocol: The higher data rates of 802.11 aft and 802.22 give the luxury of choosing from various protocols. The main criteria for the selection of a protocol were the overhead, efficiency, and security. The XMPP-IOT Protocol was chosen based on the above-mentioned criteria. The XMPP-IOT is a modified form of the XMPP Protocol which is very popular in Instant Messaging Services.

Description of Architecture: XMPP is an open, secure, spam-free, ad-free, decentralized alternative to consumer IM silos like AOL Instant Messenger, Windows Live Messenger, and Yahoo Instant Messenger. Under the hood, XMPP is a set of streaming XML protocols that enable any two entities on the Internet to exchange messages, presence, and other structured information in close to real time. XMPP-IOT aims to make communication machine to people and machine to machine interoperable. XMPP is used because of its stability, security and decentralized operation. Most of the connected devices are closed and have a defined business model. But it is also possible to open up sensors to be used in smart cities and wider.

\section{Implementation of a sensor - server network using 802.11 aft and XMPP:}

A primitive form of the network consists of a server and a trusted device (i.e.: the sensor). The basic concept of using XMPP is the notion of friends. To exchange data between two devices they need to be friends. The concept of "friends" gives the layer of security required in the use of sensitive systems. The sensor is given a JID (Jabber ID) or a X.509 certificate (verified over the HTTPS Protocol) to make it a trusted device. A simple script (using Python, Node.js or JavaScript) can be used to interface between the server and the trusted device. The data from the device can be read and control values can be sent to the various actuators using the XMPP Protocol. Since a sensor can't connect directly to $802.11 \mathrm{aft}$ Wi-Fi networks, a PCB with a built-in microcontroller which supports the XMPP Protocol is required between the sensor and the Server. In the case of several sensors being close to each other, the various sensors can connect to the same microcontroller either wirelessly or through wires in order to communicate with the server. This process makes communication between the devices more secure than in the more common IOT devices found in the market today while still being reasonably simple. This approach is scalable. Hence any future additions or upgradation of the sensors would never be a tough task.

\section{v. Results and Discussions}

TABLE I. COAL TRANSPORTATION

Laser Sensor - Primary and Secondary bunker threshold value is 500 (capacity 1000 Tonnes); on belt gamma sensor's output signals is either 1 or 0; Temperature Sensor - Threshold value is 250 (Bituminous coal - glow point is 457 degree Celsius)

\begin{tabular}{|c|c|c|c|l|}
\hline $\begin{array}{c}\text { Laser } \\
\text { Sensor - } \\
\text { Primary } \\
\text { bunker }\end{array}$ & $\begin{array}{c}\text { On belt } \\
\text { gamma } \\
\text { sensor }\end{array}$ & $\begin{array}{c}\text { Laser } \\
\text { Sensor- } \\
\text { Seconda } \\
\text { ry } \\
\text { bunker }\end{array}$ & $\begin{array}{c}\text { Temperat } \\
\text { ure } \\
\text { Sensor }\end{array}$ & \multicolumn{1}{|c|}{ Status } \\
\hline 750 & 1 & 750 & 200 & Conveyor belt is OFF \\
\hline 450 & 1 & 750 & 200 & $\begin{array}{l}\text { Conveyor belt feeds the } \\
\text { primary bunker }\end{array}$ \\
\hline 450 & 0 & 750 & 200 & $\begin{array}{l}\text { Secondary bunker fills the } \\
\text { conveyor and in turn fills } \\
\text { the primary bunker }\end{array}$ \\
\hline 750 & 1 & 450 & 200 & $\begin{array}{l}\text { Secondary bunker sends a } \\
\text { signal to local control } \\
\text { station to fill the secondary } \\
\text { bunker from the coal bunds }\end{array}$ \\
\hline 750 & 1 & 750 & 300 & $\begin{array}{l}\text { Temperature sensors sends a } \\
\text { signal to start the sprinkler } \\
\text { system to avoid firing in the } \\
\text { coal bunds. }\end{array}$ \\
\hline
\end{tabular}

TABLE II. MONITORING THE MOTORING ACTION

$\mathrm{g}$ - Measures the position of the sensor with respect to gravity

\begin{tabular}{|c|c|c|c|c|c|c|c|c|c|}
\hline \multicolumn{4}{|c|}{$\begin{array}{l}\text { Current reading of } \\
\text { accelerometer }\end{array}$} & \multicolumn{4}{|c|}{$\begin{array}{l}\text { Previous reading of } \\
\text { accelerometer }\end{array}$} & \multirow{2}{*}{$\begin{array}{c}\text { Diff } \\
\text { eren } \\
\text { ce }\end{array}$} & \multirow[t]{2}{*}{ Status } \\
\hline Deg & $\begin{array}{c}X \\
(g)\end{array}$ & $\begin{array}{c}Y \\
(g)\end{array}$ & $Z(g)$ & Deg & $\begin{array}{c}X \\
(g)\end{array}$ & $\begin{array}{c}Y \\
(g)\end{array}$ & $\begin{array}{l}Z \\
(g)\end{array}$ & & \\
\hline $\begin{array}{c}0 / \\
360\end{array}$ & 0.5 & 0.5 & 1.0 & & & & & & $\begin{array}{l}\text { Initial States - } \\
\text { OFF condition }\end{array}$ \\
\hline 90 & 0.5 & 1.0 & 0.5 & 90 & 0.0 & 0.5 & 0.5 & Yes & $\begin{array}{l}\text { Transient } \\
\text { Condition }\end{array}$ \\
\hline 180 & 0.5 & 0.5 & 0.0 & 180 & 0.0 & 0.5 & 0.5 & Yes & $\begin{array}{l}\text { Motor is } \\
\text { Running }\end{array}$ \\
\hline 270 & 0.5 & 0.0 & 0.5 & 270 & 0.0 & 0.5 & 0.5 & Yes & $\begin{array}{l}\text { Motor is } \\
\text { Running }\end{array}$ \\
\hline 270 & 0.5 & 0.0 & 0.5 & 270 & 0.0 & 0.0 & 0.0 & No & Not Running \\
\hline 270 & 0.5 & 0.0 & 0.5 & 270 & 0.0 & 0.0 & 0.0 & No & Not Running \\
\hline
\end{tabular}

TABLE III. ESP MONITORING

\begin{tabular}{|c|c|c|c|}
\hline \multicolumn{2}{|c|}{ Particle Per Million Sensor } & $\begin{array}{c}\text { Plates currently } \\
\text { working }\end{array}$ & Status \\
\hline $\begin{array}{c}\text { Threshold } \\
\text { Value }\end{array}$ & $\begin{array}{c}\text { Sensor } \\
\text { Reading }\end{array}$ & None & $\begin{array}{c}\text { No plates are being } \\
\text { operated }\end{array}$ \\
\hline 0 & 0 & 1 and 8 & 2 plates are operated \\
\hline 250 & 153 & $1,2,7$ and 8 & 4 plates are operated \\
\hline 500 & 456 & $1,2,3,6,7$ and 8 & 6 plates are operated \\
\hline 750 & 652 & $1,2,3,4,5,6,7$ and 8 & 8 plates are operated \\
\hline 1000 & 987 & &
\end{tabular}


Proc. of the Sixth International Conference on Advances in Computing, Electronics and Communication - ACEC 2017. Copyright $($ Institute of Research Engineers and Doctors. All rights reserved.

ISBN: 978-1-63248-138-2 doi: 10.15224/ 978-1-63248-138-2-02

TABLE IV. SENSOR SELECTION [2]

\begin{tabular}{|c|c|c|c|c|c|}
\hline $\begin{array}{l}\text { Sensor } \\
\text { Type }\end{array}$ & $\begin{array}{l}\text { Energy } \\
\text { Source }\end{array}$ & $\begin{array}{l}\text { Network } \\
\text { type }\end{array}$ & $\begin{array}{l}\text { Traffic } \\
\text { Rate }\end{array}$ & $\begin{array}{c}\text { Toler } \\
\text { able } \\
\text { Delay }\end{array}$ & Feasibility \\
\hline $\begin{array}{l}\text { Temper } \\
\text { ature } \\
\text { Sensor }\end{array}$ & $\begin{array}{c}\text { Battery } \\
\text { powered }\end{array}$ & Wi-Fi & $\begin{array}{l}1 \text { pkt } \\
\text { every } \\
10 \text { sec } \\
\text { per } \\
\text { device }\end{array}$ & $\begin{array}{c}30 \mathrm{sec} \\
\text { for } \\
\text { data, } \\
10 \mathrm{sec} \\
\text { for } \\
\text { alarm }\end{array}$ & $\begin{array}{l}\text { Does not present major } \\
\text { difficulties, but requires } \\
\text { intervention on existing } \\
\text { accuracy levels }\end{array}$ \\
\hline $\begin{array}{c}\text { Laser } \\
\text { Sensors }\end{array}$ & $\begin{array}{c}\text { Battery } \\
\text { powered }\end{array}$ & $\begin{array}{l}\text { Ethernet, } \\
\text { Wi-Fi }\end{array}$ & $\begin{array}{c}1 \text { pkt } \\
\text { every } 5 \\
\text { min } \\
\text { per } \\
\text { device }\end{array}$ & $\begin{array}{l}10 \\
\text { min } \\
\text { for } \\
\text { data }\end{array}$ & $\begin{array}{l}\text { Possible to realize, but } \\
\text { requires more attention } \\
\text { to get better accuracy }\end{array}$ \\
\hline $\begin{array}{l}\text { On belt } \\
\text { gamma } \\
\text { sensor }\end{array}$ & $\begin{array}{c}\text { Electrica } \\
\text { lly } \\
\text { powered } \\
-3 \\
\text { Phase } \\
\text { AC } \\
\text { Systems }\end{array}$ & $\begin{array}{l}\text { Ethernet, } \\
\text { Wi-Fi, } \\
\text { 3G, 4G }\end{array}$ & $\begin{array}{c}1 \text { pkt } \\
\text { every } \\
10 \text { sec } \\
\text { per } \\
\text { device }\end{array}$ & $\begin{array}{c}5 \text { min } \\
\text { for } \\
\text { data }\end{array}$ & $\begin{array}{c}\text { Does not present major } \\
\text { difficulties }\end{array}$ \\
\hline $\begin{array}{l}\text { Acceler } \\
\text { ometer }\end{array}$ & $\begin{array}{c}\text { Battery } \\
\text { powered }\end{array}$ & Wi-Fi & $\begin{array}{c}1 \text { pkt } \\
\text { every } \\
10 \mathrm{sec} \\
\text { per } \\
\text { device }\end{array}$ & $\begin{array}{l}1 \mathrm{~min} \\
\text { for } \\
\text { data }\end{array}$ & $\begin{array}{l}\text { Easy to realize, but } \\
\text { graph may be } \\
\text { difficult to integrate }\end{array}$ \\
\hline
\end{tabular}

\section{vI. Conclusion and Future Work}

The Centralized control of power generation industries is crucial in without the advanced communication and data processing techniques. This paper presents a novel solution for a fully automated system using IoT technology. The proposed framework introduces an IoT-based fully process automated system architecture and communication protocol for increasing the work efficiency of thermal power plants. The communication part deals with a large amount of heterogeneous data and provides a data interface. A simulated case study of this application shows that the system performs well in the real power production plants. The proposed system architecture offers enough flexibility to integrate new hardware and software capabilities. This technology can be well applied to other similar industrial environments for realtime controlling.

Our future research will focus on applying advanced communication protocol and machine learning techniques to improve the functionality and performance of the proposed system - Every node is made to learn itself in a way to find the useful data through metacognitive learning methods [3]. This can be further extended to infer results from the opted data through supervised and reinforced learning.

\section{Acknowledgement}

The authors would like to thank Dr.KR.Santha, VicePrincipal \& Head of the Department Electrical and Electronics Engineering, Sri Venkateswara college of Engineering, for the support in the realization of the "Automation of Thermal Power plants using IoT" project. The authors are also grateful to the management of Sri Venkateswara College of
Engineering (http://www.svce.ac.in) for their invaluable support.

\section{References}

[1] Feng Zhang, Student Member, IEEE, Min Liu, Member, IEEE, Zhuo Zhou, and Weiming Shen, Fellow, IEEE - "An IoT Based Online Monitoring System for Continuous Steel Casting", IEEE Internet of Things Journal, DOI 10.1109/JIOT.2016.2600630

[2] Andrea Zanella, Senior Member, IEEE, Nicola Bui, Angelo Castellani, Lorenzo Vangelista, Senior Member, IEEE, and Michele Zorzi, Fellow, IEEE - "Internet of Things for Smart Cities", IEEE INTERNET OF THINGS JOURNAL, VOL. 1, NO. 1, FEBRUARY 2014

[3] R. Savitha, S. Suresh and N. Sundararajan, "Projection-Based Fast Learning Fully Complex-Valued Relaxation Neural Network ," IEEE Transactions on Neural Networks, Vol.24, No.4, pp. 529- 54 , April 2013

[4] R. C. A. Alves, L. B. Gabriel, d. O. B. Trevizan, and C. Borges Margi, "Assisting physical (hydro) therapy with Wireless Sensors Networks," Internet of Things Journal IEEE, vol. 2, no. 2, pp. 113-120, 2015.

[5] J. A. Stankovic, "Research directions for the Internet of Things," Internet of Things Journal IEEE, vol. 1, no. 1, pp.3-9, 2014

[6] P. Marie, T. Desprats, S. Chabridon, M. Sibilla, and C. Taconet, "From ambient sensing to IoT-based context computing: An open framework for end to end QoC management," Sensors, vol. 15, no. 6, pp. 1418014206, 2015.

[7] L. Atzori, A. Iera, and G. Morabito, "The internet of things: A survey,"Comput. Netw., vol. 54, no. 15, pp. 2787-2805, 2010.

[8] R. Bonetto, N. Bui, V. Lakkundi, A. Olivereau, A. Serbanati, and M. Rossi, "Secure communication for smart IoT Objects: Protocol stacks, use cases and practical examples" in Proc. IEEE IoT-SoS, San Francisco, CA, USA, 2012.

[9] R. Savitha, S. Suresh and N. Sundararajan, "Metacognitive Learning in a Fully Complex-Valued Radial Basis Function Neural Network,", Neural Computation, vol. 24, no. 5, pp. 1297-1328, 2012.

About Author (s):

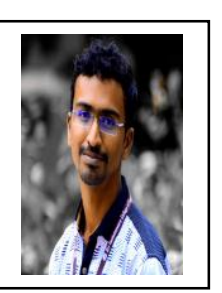

A.Harish is a student of Electrical and Electronics Engineering from Sri

Venkateswara College of Engineering His research interests comprise Computer Networks, Artificial Intelligence. He is a member of IEEE and IRED

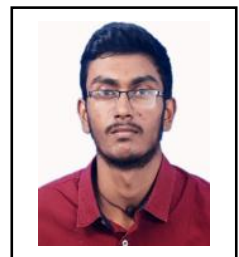

S.Ashwin is a student of Electrical and Electronics Engineering from Sri

Venkateswara College of Engineering His research interests comprise Artificial Intelligence and control systems. He is a member of IEEE.

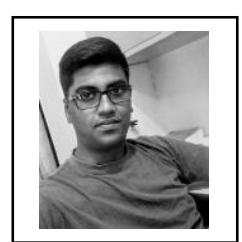

S. Arun Senthil is a student of Chemical Engineering from Sri Venkateswara College of Engineering His research interests comprise Process Systems Engineering and Applied Mathematics. He is a member of AIChE 